\title{
STABILITY ANALYSIS OF UNFAVOURABLE GEOLOGICAL BODIES IN A POST-EARTHQUAKE AREA: A CASE STUDY IN GENGDA TOWNSHIP CHINA
}

\author{
ZHONG, W. ${ }^{1,2}-$ HE, N. ${ }^{3,4^{*}}-$ MEI, Z. ${ }^{5}-$ KHAN, M. A. ${ }^{6}$ \\ ${ }^{1}$ Key Laboratory of Mountain Hazards and Surface Processes, Chinese Academy of Sciences, \\ Chengdu 610041, China \\ ${ }^{2}$ Institute of Mountain Hazards and Environment, Chinese Academy of Sciences, Chengdu \\ 610041, China \\ ${ }^{3}$ School of Civil Engineering, Henan Polytechnic University, Jiaozuo, Henan 454000, China \\ ${ }^{4}$ International Joint Research Laboratory of Henan Province for Underground Space \\ Development and Disaster Prevention, Jiaozuo, Henan 454000, China \\ ${ }^{5}$ Henan College of Industry and Information Technology, Jiaozuo, Henan 454003, China \\ ${ }^{6}$ Karakoram International University, Gilgit-Baltistan, Pakistan \\ *Corresponding author \\ e-mail:hn61886@163.com \\ (Received 23 $3^{\text {rd }}$ Feb 2019; accepted $3^{\text {rd }}$ May 2019)
}

\begin{abstract}
On 12 May 2008, a devastating mega-earthquake of magnitude 8.0 struck the Wenchuan area, northwestern Sichuan Province, China. Following this earthquake event, many areas in the affected areas were susceptible to geological disasters, such as debris flows, landslides and other secondary disasters. To better understand the mechanism of the formation processes of geological disasters, and to reduce the economic loss caused by the disasters, a comprehensive analysis is required. With the aim of obtaining the characteristics of unfavourable geological bodies, and analysing their stability, we choose the Gengda Township as an example (there are many unfavourable geological bodies distributed in this area, including landslides and deformation bodies). Field investigations and computational models are employed to analyse the stability of the unfavourable geological bodies. Through preliminary analysis and model calculation, the following conclusions can be drawn: under natural conditions, the stability factor of the landslide ranges from about 1.02-1.03, which means that the landslide is in a basically stable or less stable condition. Under the effect of continuous heavy rainfall, the stability factor of the landslide will be significantly reduced, and the corresponding value ranges from $0.9-0.96$, which signifies that the landslide is in an unstable condition. For No 1 and No 2 deformation bodies (named by local inhabitants), the stability varied from less stable to unstable, and basically stable to unstable, respectively. On the basis of the results of the calculation, some countermeasures are proposed to mitigate the effects of these disasters probably caused by geological bodies.
\end{abstract}

Keywords: case study, stability, model calculation, safety factor, transfer coefficient method

\section{Introduction}

The 2008 Wenchuan Earthquake in Sichuan Province, China generated many unfavourable geological bodies, which can provide a huge amount of loose deposits, which have caused a dramatic increase in debris-flow occurrence in subsequent years (Hu et al., 2016; Tang et al., 2009; Zhuang et al., 2013). The epicenter Wenchuan Earthquake was in Wenchuan County, Sichuan $\left(31^{\circ} 1^{\prime} 15.60^{\prime \prime} \mathrm{N}, 103^{\circ} 22^{\prime} 1.20^{\prime \prime} \mathrm{E}\right)$. As a consequence of the severe shocks, most valleys and slopes were destabilized and 
numerous geo-hazards, such as landslides, collapses, and unstable slopes, were triggered in the earthquake-affected area, which covered 50 badly affected counties and ten worst-affected counties in Sichuan province, SW China (Chen et al., 2009; Lee et al., 2017; Wang et al., 2017). The earthquake-stricken area is also the key area for torrent and debris flow mitigation in Sichuan. It was observed that the availability of masses of loose materials was the most important contributing factor for debris flows. Therefore, rock avalanches and landslides induced by the earthquake would supply abundant solid materials to form subsequent debris flows (Chen et al., 1989; Jiayuan, 1995; Postance et al., 2017; Sun et al., 2016). Gengda township is located in the worststricken area, Wenchuan earthquake not only caused a lot of casualties and economic losses, but also induced numerous secondary geological disasters, which including collapses, landslides and debris flows (Ni et al., 2012). As triggered by the Wenchuan earthquake, abundant rock falls and landslides were deposited in the gully drainages, which could provide a large amount of loose solid materials that might be directly turned into debris flows or easily entrained by debris flows. The abundant loose solid materials produced by an earthquake is usually recognized as the most important factor contributing to the occurrence of debris flow. Furthermore, the threshold of trigger factors, such as rainfall, significantly decreases after earthquake events. Thus, areas affected by the Wenchuan earthquake were prone to geological disasters ( $\mathrm{Ni}$ et al., 2011; Zhuang et al., 2010; Kang and Kim, 2016; Shima et al., 2016).

Through field investigations, the lithology, seismic activity, and tectonic movements of the study area can be determined and consist of the following: exposed strata mainly concentrated in the Quaternary alluvial layer $\left(\mathrm{Q}_{4}{ }^{\mathrm{al}+\mathrm{pl}}\right)$, the eluvial layer $\left(\mathrm{Q}_{4}{ }^{\mathrm{el}+\mathrm{dl}}\right)$, colluvium $\left(\mathrm{Q}_{4}{ }^{\mathrm{col}}\right)$, and the landslide deposition layer $\left(\mathrm{Q}_{4}{ }^{\mathrm{del}}\right)$. Moreover, the bedrock in the study area is fragmentized due to the effect of tectonic movement and weathering, which can greatly facilitate landslide movement in subsequent rainfall conditions.

The study area is located in Huaxia tectonic belt, which belongs to Longmenshan tectonic system, and the tectonic movement is extremely complex. Due to the effect of strong tectonic movements, the bedrock becomes loose and can thus provide favourable conditions for the development of collapse, landslides, and other geological disasters.

On 12 May 2008, a devastating mega-earthquake of magnitude 8.0 struck the Wenchuan area of northwestern Sichuan Province, China. The focal mechanism of the earthquake was successive massive rock fracturing at $15 \mathrm{~km}$ depth at Yingxiu. Seismic analysis confirmed that the major shock occurred on the Beichuan-Yingxiu Fault and that aftershocks rapidly extended in a straight northeast-southeast direction along the Longmenshan Fault zone. The total number of fatalities approached 15000, with a significant number resulting from seismically triggered geohazards (Cui et al., 2011). The study area is located in Longmenshan seismic zone. Several earthquakes hit this area before the 12 May 2008 Wenchuan earthquake, including the 1933 Diexi earthquake (with a magnitude of 7.5), the 1657 Wenchuan earthquake (with a magnitude of 6.5), and the 1976 Pingwu earthquake (with a magnitude of 7.2). The study area influenced by these earthquakes reached degree $\mathrm{V}$.

In order to mitigate the disasters that were caused by unfavourable geological bodies after the Wenchuan earthquake, field investigations and calculation models are employed in this paper to analyse the stability of the unfavourable bodies. After analysis, the stability of the unfavourable bodies can be identified, and the corresponding engineering countermeasures can be proposed. Thus, the magnitude of 
the disasters caused by the unfavourable bodies can be significantly reduced, and the security of the inhabitants living adjacent to the unfavourable bodies can be guaranteed.

\section{Materials and methods}

\section{Study area}

Wenchuan earthquake of 12 May 2008 which caused numerous coseismic landslides. After earthquakes of this magnitude, most valleys and slopes are destabilized and conditions for debris flows and landslides are amplified. These hazards are typically very active during the following 10-20 years. As a consequence of the severe shocks, most valleys and slopes were destabilized and numerous geo-hazards, such as landslides (Fig. 1), collapses (Fig. 2a), and unstable slopes (Fig. 2b), were triggered in the earthquake-affected area, which covered 50 badly affected counties and ten worstaffected counties in Sichuan province, SW China (Chen et al., 2009). The Gengda township is located in an earthquake-stricken area; due to the effect of seismic activity, many slopes located in the Gengda township are seriously affected. Thus, in the subsequent rainy seasons, these unfavourable bodies can be transferred into secondary disasters in response to heavy rainfall. The main objective of this paper is twofold. First, through field investigation, the fundamental data of the study area and the distribution of the unfavourable bodies can be identified; then, computational models are employed to compute the safety factor of each slope, which could allow us to analyse the stability of the slopes distributed within the study area. On the basis of the model calculations, the risk of each slope can be mapped, and preventative engineering can be designed. Thus, the threat caused by the unfavourable bodies can be greatly reduced.

\section{Characteristics of the unfavourable geological bodies}

The unfavourable geological bodies in the Gengda township mainly fall into the following four types: landslides, slippery bodies, deformation bodies, and perilous rock. These unfavourable geological bodies cause a great risk to the security of the nearby inhabitants. Moreover, many facilities are also under their threat (Table 1). In order to compute the safety factors of the unfavourable geological bodies, field investigations were conducted meticulously. Through these investigations, the fundamental data of the study area could be obtained, including meteorological data, geological conditions, topography, rainfall data, tectonic and earthquake history, hydrological conditions, and human activity. With the help of the data obtained through field investigations, the stability of the bodies can be analysed preliminarily. Then, calculation models are employed to compute the corresponding safety factors of he bodies. By comparing the calculation results to preliminary analysis results, the stability of the unfavourable geological bodies can be reasonably analysed.

\section{Methods}

In this paper, two basic approaches (field investigations and model calculations) are employed to explore the stability of the unfavourable bodies. The field investigations can help us acquire data that are closely related with the unstable bodies, which will be useful and can greatly facilitate the subsequent model calculation processes. Based on the fundamental data of the study area and the results of model calculations, a comprehensive stability analysis of each body can be performed. 


\section{Field investigations}

The field investigations were conducted from the period between June 2009 and July 2009, and these work lasted for around one month. Our investigations are primarily concentrate in Gengda township, Wenchuan prefecture, Sichuan Province. During the processes of investigations, we mainly collected the data with regard to rainfall conditions, geological conditions, topography, etc. The main purpose of the field investigations concerned the following main issues: an initial consideration of the distribution, scale, geological conditions, and triggering factors of each unstable body, followed by a preliminary analysis of the formation mechanism of each unstable body alongside an evaluation of its stability. These results can be compared with subsequent model computations, which can help us to draw reasonable and accurate conclusions. These conclusions can provide a reliable geological basis for designing preventative engineering measures for each unstable body. With the help of Wolong Reserve Management Bureau, Wolong Land Resources Bureau, and Wolong township government, field investigations were conducted and lasted for around one month. The scope of the investigations not only concentrated on the unstable body itself but also included the adjacent zone (within a 20 metre radius) and the area susceptible to these unstable bodies. Through the field investigations, it was possible to acquire the fundamental data of the study area, which are described in the following sections.
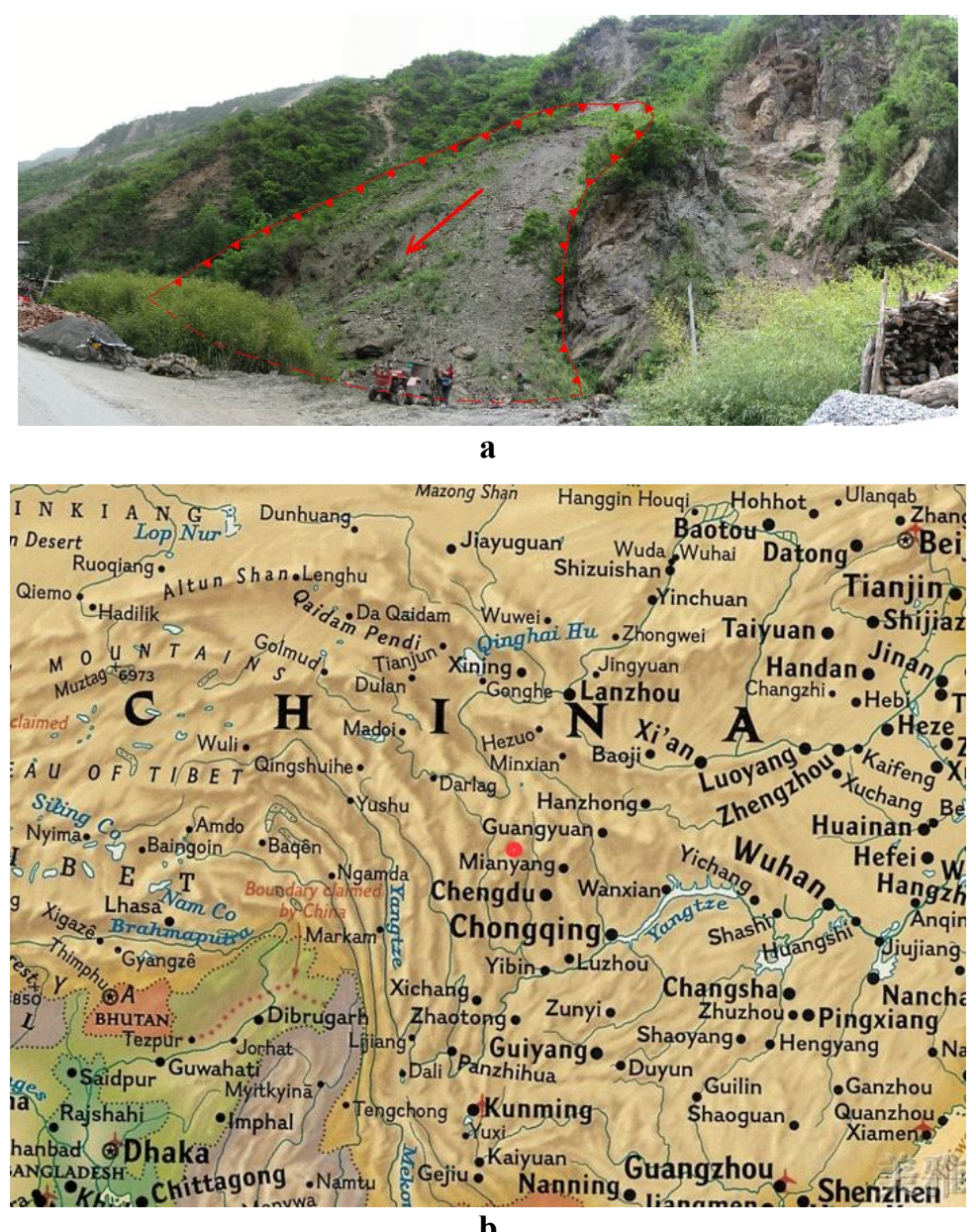

Figure 1. Full view of Nitianguo landslide (red point is the study area). a Landslide range, $\boldsymbol{b}$ location of the study area 


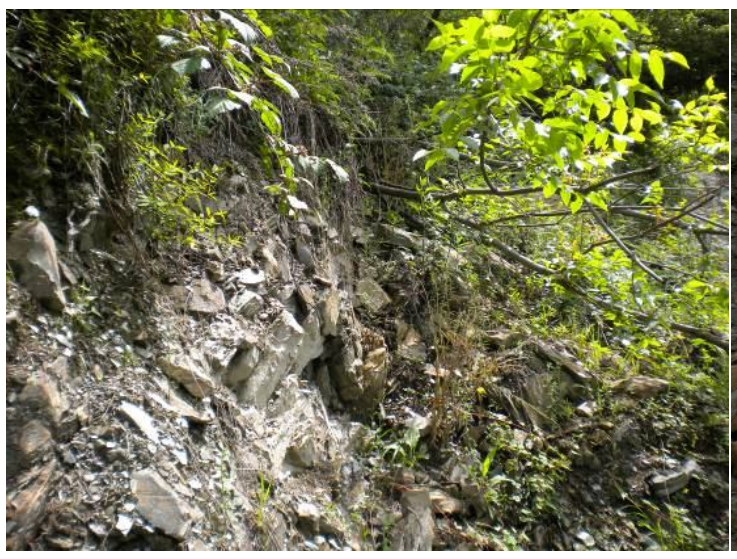

a

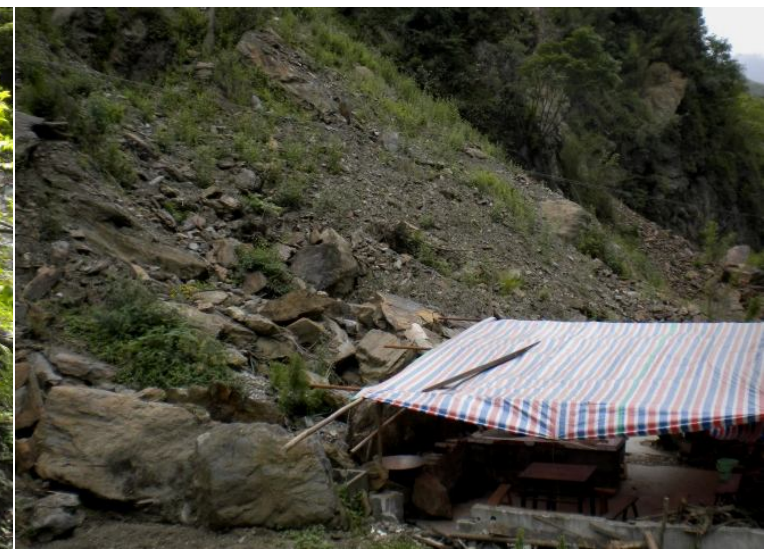

b

Figure 2. Other types of unstable geological bodies. a Collapses, $\boldsymbol{b}$ unstable slopes

Table 1. Number of buildings and inhabitants under the threat of unfavourable geological bodies in Gengda township

\begin{tabular}{|c|c|c|c|c|c|}
\hline $\begin{array}{l}\text { Object under threat } \\
\text { of unfavourable } \\
\text { geological bodies } \\
\end{array}$ & Name of household & Inhabitants & $\begin{array}{c}\text { Area of } \\
\text { building }\left(\mathrm{m}^{2}\right)\end{array}$ & \begin{tabular}{|c|}
$\begin{array}{c}\text { Potential } \\
\text { economic loss } \\
\left(10^{4}\right)\end{array}$ \\
\end{tabular} & Notes \\
\hline \multirow{13}{*}{ Gengda township } & Shunfang Liu & 5 & 230 & 10 & \\
\hline & Qing Jian & 4 & 300 & 20 & $\begin{array}{l}\text { Original } \\
\text { building was } \\
\text { damaged }\end{array}$ \\
\hline & Xing Jian & 4 & 140 & 8 & \\
\hline & Lin Jian & 5 & 380 & 30 & \\
\hline & Fugui Yu & 4 & 400 & 12 & \\
\hline & Tianguo Ni & 5 & 500 & 180 & \\
\hline & Shaoxiu Zhou & 10 & 600 & 20 & \\
\hline & Tianyuan Ni & 5 & 400 & 15 & \\
\hline & Tianhua Ni & 5 & 150 & 12 & \\
\hline & Wenxiang Tang & 6 & 150 & 4 & \\
\hline & Bing Jian & 5 & 120 & 10 & $\begin{array}{c}\text { Under } \\
\text { construction }\end{array}$ \\
\hline & $\begin{array}{l}\text { Huachuan Gong } \\
\text { Highway Construction } \\
\text { Group Co., Ltd. } 303 \\
\text { Project Department }\end{array}$ & 50 & $\begin{array}{l}\text { Rented } \\
\text { building }\end{array}$ & 200 & \\
\hline & $\begin{array}{c}\text { Workers of Huachuan } \\
\text { Gong Highway } \\
\text { Construction Group Co., } \\
\text { Ltd }\end{array}$ & 50 & $\begin{array}{l}\text { Rented } \\
\text { building }\end{array}$ & 5 & \\
\hline $\begin{array}{c}\text { Transmission } \\
\text { facilities }\end{array}$ & Transmission tower & & & 60 & \\
\hline $\begin{array}{c}\text { Disaster prevention } \\
\text { facilities } \\
\end{array}$ & $\begin{array}{c}\text { Retaining wall } \\
(2 \times 8 \times 85 \mathrm{~m})\end{array}$ & & 85 & & $\begin{array}{c}\text { Under } \\
\text { construction }\end{array}$ \\
\hline Highway & Highway 303 & & 500 & 150 & \\
\hline Number & \multicolumn{3}{|c|}{$\begin{array}{l}11 \text { households, } 58 \text { people, floating population } 100,2 \\
\text { transmission towers and } 500 \mathrm{~m} \text { highway }\end{array}$} & 736 & \\
\hline
\end{tabular}




\section{Model calculations}

Since most slopes and other deformable bodies distributed within the study area mainly consist of soil, the deformation of the slope is mainly governed by the weak interface with maximum shear stress. Therefore, we can use the Transfer Coefficient Method (GB 50330-2013) to compute the safety factors of the slopes. Following this method, and to facilitate the subsequent deducing processes, the soil is initially divided vertically into several strips (Fig. 3) and each strip is taken as a rigid body while taking the interaction forces between the strips into consideration at the same time. The deducing results can be employed to calculate the safety factor of each strip from the slope, and the safety factor of the whole slope can be determined. On the basis of the above description, we assumed that the residual sliding force was parallel to the sliding surface, and then the driving moment and the resisting moment exerted on individual strips can be calculated, as shown by the stress analysis diagram in Figure 3.

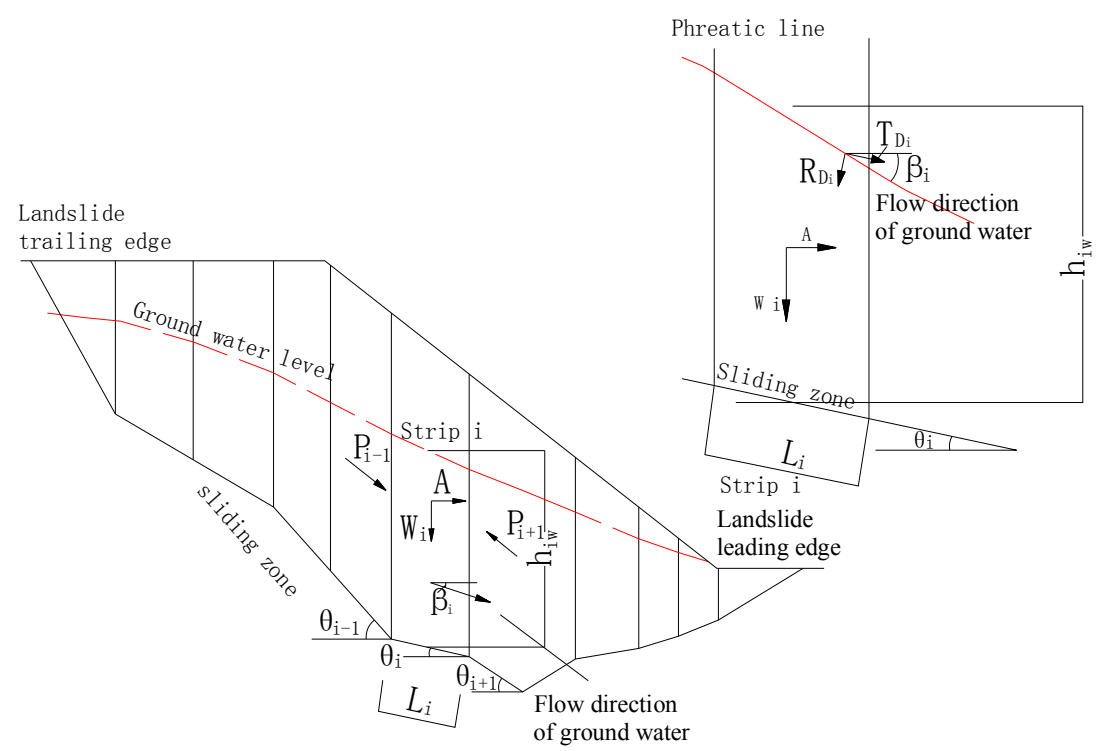

Figure 3. Calculation model of transfer coefficient method

(1) The computational formula for computing the safety factor is expressed as follows:

$$
\begin{gathered}
K_{f}=\frac{\sum_{i=1}^{n-1}\left(\left(W_{i}\left(1-r_{u}\right) \cos \theta_{i}\right) \operatorname{tg} \phi_{i}+C_{i} L_{i} \prod_{j=i}^{n-1} \psi_{j}\right)+R_{n}}{\sum_{i=1}^{n-1}\left(W_{i}\left(\sin \theta_{i}+A \cos \theta_{i}\right) \prod_{j=i}^{n-1} \psi_{j}\right)+T_{n}} \\
R_{i}=\left(W_{i}\left(\left(1-r_{U}\right) \cos \theta_{i}-A \sin \theta_{i}\right)-R_{D i}\right) \operatorname{tg} \phi_{i}+C_{i} L_{i} \\
T_{i}=W_{i}\left(\sin \theta_{i}+A \cos \theta_{i}\right)+T_{D i} \\
\prod_{j=i}^{n-1} \psi_{j}=\psi_{i} \psi_{i+1} \cdots \cdots \psi_{n-1}
\end{gathered}
$$


$\psi_{i}$ is the residual sliding force transferred from strip $\mathrm{i}$ to strip $\mathrm{i}+1(j=i)$; that is:

$$
\Psi_{i}=\cos \left(\theta_{i}-\theta_{i+1}\right)-\sin \left(\theta_{i}-\theta_{i+1}\right) \tan \phi_{i+1}
$$

where $W_{i}$ is the weight of the $\mathrm{i}$-th strip; $T_{i}$ is the sliding force of the $\mathrm{i}$-th strip; $R_{i}$ is the resistance force of the $\mathrm{i}$-th strip; $\theta_{i}$ is the inclination of the sliding surface of the $\mathrm{i}$-th strip; $\beta_{i}$ is the angle between the sliding surface and the ground water (here, ground water denotes the water level below the $\mathrm{i}$-th strip); $\psi_{i}$ is the cohesion forces of the $\mathrm{i}$-th strip; $\phi_{i}$ is the internal friction angle of the $\mathrm{i}$-th strip; $L_{i}$ is the length of the sliding surface of $\mathrm{i}$-th strip; $A$ is the coefficient of earthquake acceleration in the area where the seismic fortification grade is level $6, \mathrm{~A}$ is equal to $0.05 ; R_{D i}$ is the component of seepage force perpendicular to the sliding surface, and $R_{D i}$ is equal to $N_{W i} \tan \beta_{i} \sin \left(\alpha_{i}-\beta_{i}\right) ; T_{D i}$ is the component of seepage force parallel to the sliding surface, and $T_{D i}$ is equal to $N_{W i} \tan \beta_{i} \cos \left(\alpha_{i}-\beta_{i}\right) ; N_{W i}$ is pore water pressure, and $N_{W i}$ is equal to $\gamma_{W} h_{i W} L_{i} ; r_{U}$ is the ratio of pore pressure, and $r_{U}=\frac{v_{w} \times \gamma_{w}}{v_{s} \times \gamma_{s}} \approx \frac{s_{u}}{s_{t} \times 2}$, where $v_{w}$ is the volume of the strip below water level, $v_{s}$ is the total volume of the strip, $s_{u}$ is the area of the strip below the water level, $s_{t}$ is the total area of the strip, and $\gamma_{w}$ and $\gamma_{s}$ represent the unit weight of the water and strip (sliding body), respectively.

(2) The computational formula for computing the residual sliding force is expressed as follows:

$$
P_{i}=P_{i-1} \Psi_{i-1}+K_{s} \times T_{i}-R_{i}
$$

where $P_{i}$ is the sliding thrust of the $\mathrm{i}$-th strip $(\mathrm{kN} / \mathrm{m}) ; P_{i-1}$ is the residual sliding force of i-th strip $(\mathrm{kN} / \mathrm{m})$; and $K_{s}$ is the designed safety factor, with a value of 1.15 here.

\section{Climatic and geological settings}

Climatically, the study area falls into the subtropical humid climate zone; during winter the area is significantly affected by the Qinghai-Tibet Plateau climate, while in summer it is mainly dominated by the southwest and southeast monsoon climate. The mean annual precipitation is $930.2 \mathrm{~mm}$, and the rainfall is mainly concentrated during the period from May to September, which contributes more than $78 \%$ of the total precipitation throughout the year. According to the rainfall contour diagram of Sichuan province illustrated in the manual of flood calculations for small and medium-sized basins, the rainfall data for $10 \mathrm{~min}$ and 1,6 , and $24 \mathrm{~h}$ can be acquired and the corresponding amounts are 10, 20,65, and $120 \mathrm{~mm}$, respectively. Some slopes in the study area have been loosened by the effect of seismic activity, which will result in instability under subsequent heavy rainfall conditions (Tang et al., 2011). The rainfall data from 2000 to 2009 were gathered, as shown in Table 2, and the historical rainfall histogram is shown in Figure 4. 
Table 2. Rainfall data from 2000 to 2009 (the dataset are collected from county annals)

\begin{tabular}{c|c|c|c|c|c|c|c|c|c|c|c|c|c}
\hline \multirow{2}{*}{ Year } & \multicolumn{10}{|c|}{ Rainfall (mm) } & $\begin{array}{c}\text { Annual } \\
\text { rainfall } \\
\text { (mm) }\end{array}$ \\
\hline & Jan & Feb & Mar & Apr & May & June & July & Aug & Sep & Oct & Nov & Dec & \\
\hline $\mathbf{2 0 0 0}$ & 8.0 & 13.0 & 30.0 & 122.0 & 144.0 & 122.0 & $/$ & $/$ & 29.0 & 78.0 & 46.0 & 1.0 & \\
$\mathbf{2 0 0 1}$ & 8.0 & 11.0 & 26.0 & 89.0 & 94.0 & 154.0 & 161.0 & 165.0 & 149.0 & 111.0 & 16.0 & 9.0 & 993 \\
$\mathbf{2 0 0 2}$ & 4.0 & 24.0 & 46.0 & 68.0 & 155.0 & 244.0 & 303.0 & 115.0 & 114.0 & 92.0 & 12.0 & 0 & 1177 \\
$\mathbf{2 0 0 3}$ & 7.0 & 11.0 & 32.0 & 82.0 & 96.0 & 159.0 & 207.0 & 139.0 & 123.0 & 91.0 & 15.0 & 2.0 & 964 \\
$\mathbf{2 0 0 4}$ & 6.0 & 11.0 & 24.0 & 117.0 & 97.0 & 189.0 & 152.0 & 106.0 & 168.0 & 73.0 & 28.0 & 6.0 & 977 \\
$\mathbf{2 0 0 5}$ & $/$ & $/$ & $/$ & 24.0 & 133.0 & 160.0 & 235.0 & 184.0 & 99.0 & 34.0 & $/$ & $/$ & \\
$\mathbf{2 0 0 6}$ & $/$ & $/$ & $/$ & 11.0 & 113.0 & 95.0 & 152.0 & 118.0 & 43.0 & 36.0 & 9.0 & 2.0 & \\
$\mathbf{2 0 0 7}$ & 4.0 & 33.0 & 36.0 & 83.0 & 338.0 & 146.0 & 132.0 & 9.0 & $/$ & $/$ & $/$ & $/$ & \\
$\mathbf{2 0 0 8}$ & 7.0 & 23.0 & 32.0 & 81.0 & 113.0 & 103.0 & 218.0 & 186.0 & 98.0 & 118.0 & 35.0 & 5.0 & 1019 \\
$\mathbf{2 0 0 9}$ & 4.0 & 14.0 & 16.0 & 132.0 & 141.0 & 140.0 & 195.0 & 177.0 & 132.0 & 32.0 & 41.0 & 20.0 & 1044 \\
\hline
\end{tabular}

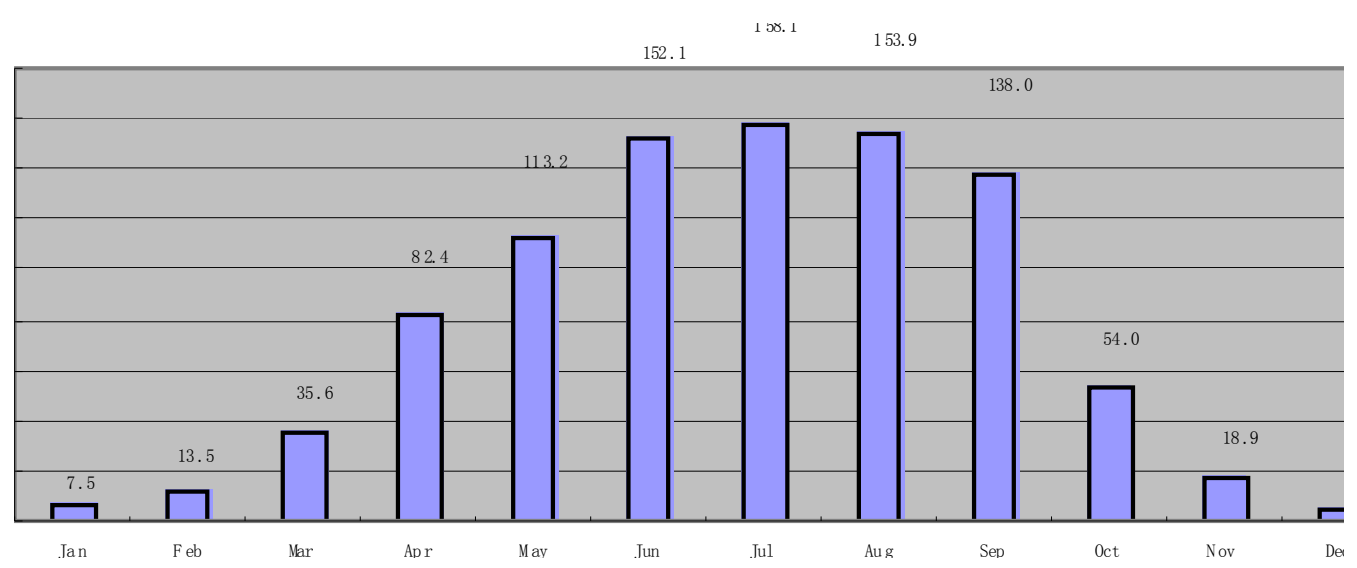

Figure 4. Histogram of historical average rainfall $(\mathrm{mm})$

\section{Determination of the load condition parameters for model calculations}

Through field investigations, the influential factors of the unstable bodies in the study area were studied meticulously. By analysis we found that the slopes in this area are mainly affected by the own weight of the slope, rainfall, and seismic activity. Based on these influential factors, we determined the load conditions and computed the safety factors under different load conditions. The load conditions were mainly grouped into three types: condition 1 represents the effect of the own weight of the slope, condition 2 represents the combined effect of the own weight of the slope and rainfall conditions $(34 \mathrm{~mm} / \mathrm{h})$, and condition 3 represents the effect under the own weight of the slope, rainfall conditions $(34 \mathrm{~mm} / \mathrm{h})$, and seismic activity.

During field investigations, we conducted some in-situ bulk density tests (we dug a hole in the field, measured the size of the hole in order to calculate the volume of the soil, and weighing the weight of the soil that was dug out, thus the unit weight can be figured out. Use similar method, we can also determine the saturated unit weight of the soil), and obtained the corresponding data, then combined with local rock-mass unit weight the unit weight of the slope body can be determined, the value of unit weight and saturated unit weight of the slope body is 17.1 and $25 \mathrm{kN} / \mathrm{m}^{3}$, respectively. Soil strength 
parameters can be obtained by laboratory experiments (direct shear tests in the laboratory were conducted to identify strength of the soil collected from study area), by experiments the shear strength under fast shear and under fully saturated shear can be acquired simultaneously, their corresponding value shown in Table 3.

Table 3. Shear strength of sliding body under different conditions

\begin{tabular}{c|c|c|c|c}
\hline \multirow{2}{*}{ Landslide } & \multicolumn{2}{|c|}{$\begin{array}{c}\text { Shear strength under natural } \\
\text { conditions }\end{array}$} & $\begin{array}{c}\text { Shear strength under fully saturated } \\
\text { conditions }\end{array}$ \\
\cline { 2 - 5 } & $\mathbf{C ~ ( k P a )}$ & $\mathbf{\Phi ~}\left(^{\circ}\right)$ & $\mathbf{C ~ ( k P a )}$ & $\mathbf{\Phi}\left(^{\circ}\right)$ \\
\hline $\begin{array}{c}\text { Sliding body and No 1 } \\
\text { deformation body }\end{array}$ & 8.5 & 29 & 7.5 & 28 \\
\hline No 2 deformation body & 3.5 & 23.5 & 2.5 & 22 \\
\hline
\end{tabular}

\section{Results and discussion}

According to the principle of the Transfer Coefficient Method, the unfavourable bodies in the study area can be vertically divided into several strips. Through preliminary analysis, we found that strips 6 and 7 are the most dangerous sliding bodies in the whole landslide, strips 1 and 2 are the most dangerous sliding bodies in No 1 deformation body, and strip 5 is the most dangerous body in No 2 deformation body. The stability calculation diagrams are shown in Figure $5 a-c$.

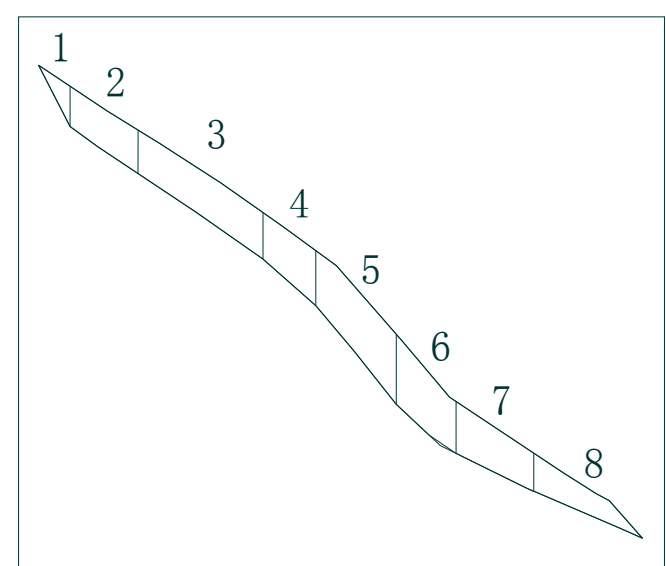

a

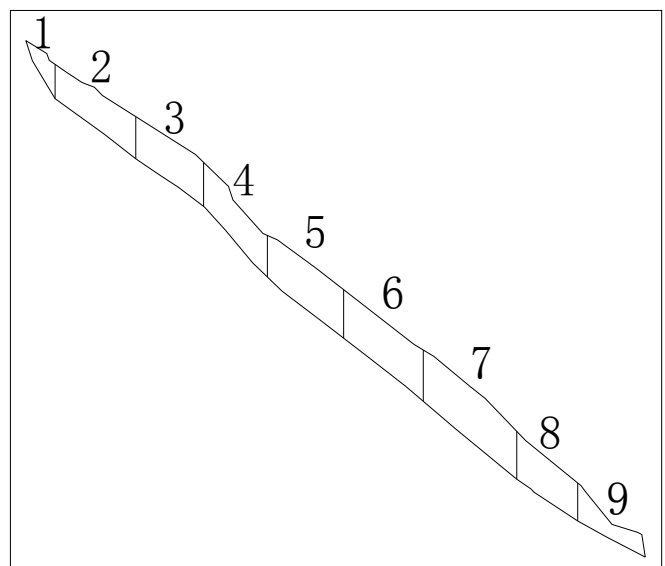

b

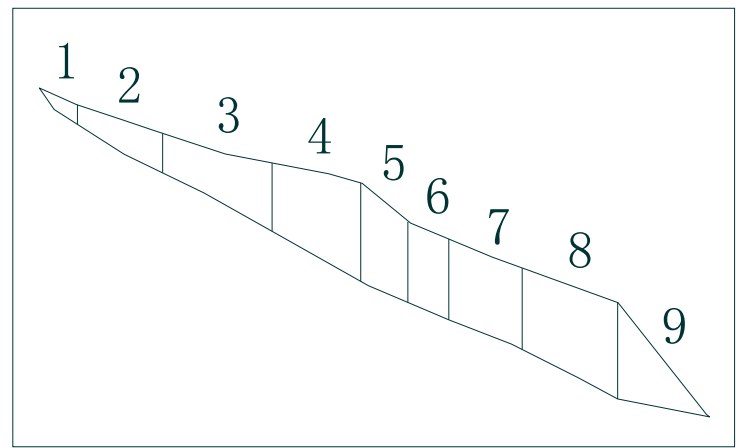

Figure 5. Stability calculation diagram of a strip 1 of No 1 deformation body (profile); $\boldsymbol{b}$ strip 2 of No 1 deformation body (profile) and c strip 5 of No 2 deformation body (profile) 
On the basis of Section 4, the calculation can be conducted and the calculation results can be obtained. Then the safety factors of strips 6 and 7 of the landslide, strips 1 and 2 of No 1 deformation body and strip 5 of No 2 deformation body can be obtained under different load conditions, as shown in Table 4. For No 1 deformation body, under the influence of the own weight of sliding body, the safety factor is 1.04, and under the effects of the own weight of sliding body and rainfall $(34 \mathrm{~mm} / \mathrm{h})$, the safety factor is 1.03 , results of the analysis can also be applied to landslide and No 2 deformation body.

Table 4. Model calculation results. Conditions 1, 2 and 3 represent the effects under the own weight of landslide, the effects under the own weight of landslide and rainfall $(34 \mathrm{~mm} / \mathrm{h})$, the effects under the own weight of landslide, rainfall $(34 \mathrm{~mm} / \mathrm{h})$, and seismic activity

\begin{tabular}{c|c|c|c|c}
\hline \multirow{2}{*}{ Load conditions unstable bodies and strips } & $\mathbf{1}$ & $\mathbf{2}$ & $\mathbf{3}$ \\
\cline { 3 - 5 } & & Safety factor & Safety factor & Safety factor \\
\hline \multirow{2}{*}{ Landslide } & 6 & 1.02 & 0.9 & 0.61 \\
& 7 & 1.13 & 0.96 & 0.66 \\
\hline \multirow{2}{*}{ No 1 deformation body } & 1 & 1.04 & 0.89 & 0.62 \\
& 2 & 1.03 & 0.89 & 0.63 \\
\hline No 2 deformation body & 5 & 1.1 & 0.92 & 0.60 \\
\hline
\end{tabular}

According to "Landslide Prevention Engineering Design and Construction of Calculation Specification", on the basis of the classification of landslide stability, the stability state under different stability factors can be determined, as shown in Table 5. With the help of Table 5, the safety factors under three different load conditions can be set as 1.30, 1.10, and 1.05, respectively. Then the residual sliding thrust can be calculated, and the calculation results are shown in Table 6.

Table 5. Classification of landslide stability (Kst is the designed safety factor) Conditions 1 , 2 and 3 represent the effects under the own weight of landslide, the effects under the own weight of landslide and rainfall $(34 \mathrm{~mm} / \mathrm{h})$, the effects under the own weight of landslide, rainfall $(34 \mathrm{~mm} / \mathrm{h})$, and seismic activity

\begin{tabular}{c|c|c|c|c}
\hline $\begin{array}{c}\text { Stability factor of } \\
\text { the slope }\end{array}$ & $\mathrm{K}_{\mathrm{s}}<1.00$ & $1.00<\mathrm{K}_{\mathrm{s}} \leq 1.05$ & $1.05<\mathrm{K}_{\mathrm{s}} \leq \mathrm{K}_{\mathrm{st}}$ & $\mathrm{K}_{\mathrm{s}} \geq \mathrm{K}_{\mathrm{st}}$ \\
\hline Stability status & Unstable & Less stable & Basically stable & Stable \\
\hline
\end{tabular}

According to landslide engineering investigation specifications, the stability of landslides can be subdivided into four classes. If the stability factor of a landslide under certain load conditions is larger than the safety factor, we can state that the stability of the landslide matches the stability criteria well. Based on this principle, the following conclusions can be drawn:

Under natural conditions, the stability factor of strip 6 is 1.02; thus referring to Table 5, the landslide is in the less stable state. Through field investigations, we found that many cracks developed at the location of strip 6. Moreover, under continuous rainfall, the stability factor decreased to 0.9 , which means that the landslide is unstable under such conditions, which is in good agreement with the preliminary analysis. Under natural conditions, the stability factor of strip 6 is 1.13; referring to Table 5, the 
landslide is in the basically stable state. Similarly, under continuous rainfall, the stability factor decreased to 0.96 , i.e. the landslide is unstable under such conditions, which is in good agreement with the real situation.

Table 6. Calculation results of the residual sliding thrust

\begin{tabular}{|c|c|c|c|c|c|}
\hline \multicolumn{2}{|c|}{$\begin{array}{c}\text { Unfavourable bodies } \\
\text { and strips }\end{array}$} & $\begin{array}{c}\text { Load } \\
\text { conditions }\end{array}$ & Safety factor $F_{s}$ & Stability factor $\boldsymbol{F}_{s t} \mid$ & $\begin{array}{l}\text { Residual sliding } \\
\text { thrust E (kN/m) }\end{array}$ \\
\hline \multirow{2}{*}{ Landslide } & No.6 & $\begin{array}{l}\text { Condition } 1 \\
\text { Condition } 2 \\
\text { Condition } 3\end{array}$ & $\begin{array}{c}1.02 \\
0.9 \\
0.61\end{array}$ & $\begin{array}{c}1.2 \\
1.10 \\
1.05\end{array}$ & $\begin{array}{c}479.22 \\
800.28 \\
2230.20\end{array}$ \\
\hline & No.7 & $\begin{array}{l}\text { Condition } 1 \\
\text { Condition } 2 \\
\text { Condition } 3 \\
\end{array}$ & $\begin{array}{l}1.13 \\
0.96 \\
0.66 \\
\end{array}$ & $\begin{array}{l}1.2 \\
1.10 \\
1.05 \\
\end{array}$ & $\begin{array}{c}87.77 \\
274.38 \\
945.36 \\
\end{array}$ \\
\hline \multirow{2}{*}{$\begin{array}{c}\text { No } 1 \text { deformation } \\
\text { body }\end{array}$} & $1-1^{\prime}$ & $\begin{array}{l}\text { Condition } 1 \\
\text { Condition } 2 \\
\text { Condition } 3 \\
\end{array}$ & $\begin{array}{l}1.04 \\
0.89 \\
0.62 \\
\end{array}$ & $\begin{array}{l}1.2 \\
1.10 \\
1.05 \\
\end{array}$ & $\begin{array}{c}222.72 \\
433.78 \\
1139.49 \\
\end{array}$ \\
\hline & $2-2^{\prime}$ & $\begin{array}{l}\text { Condition } 1 \\
\text { Condition } 2 \\
\text { Condition } 3 \\
\end{array}$ & $\begin{array}{l}1.03 \\
0.89 \\
0.63 \\
\end{array}$ & $\begin{array}{c}1.2 \\
1.10 \\
1.05 \\
\end{array}$ & $\begin{array}{c}348.58 \\
634.06 \\
1580.44 \\
\end{array}$ \\
\hline $\begin{array}{c}\text { No } 2 \text { deformation } \\
\text { body }\end{array}$ & $5-5^{\prime}$ & $\begin{array}{l}\text { Condition } 1 \\
\text { Condition } 2 \\
\text { Condition } 3\end{array}$ & $\begin{array}{l}1.10 \\
0.92 \\
0.60\end{array}$ & $\begin{array}{c}1.2 \\
1.10 \\
1.05\end{array}$ & $\begin{array}{c}55.34 \\
147.33 \\
511.87\end{array}$ \\
\hline
\end{tabular}

Under natural conditions, the safety factors of strips 1 and 2 of No 1 deformation body are 1.04 and 1.03, respectively. Referring to Table 5, the No 1 deformation body is in the less stable state. These findings agreed well with preliminary analysis. Under continuous rainfall, the stability factors of strips 1 and 2 both decreased to 0.89 , meaning that the No 1 deformation body is unstable under such conditions, which is in good agreement with the real situation.

Under natural conditions, the safety factor of strip 5 of No 2 deformation body is 1.10. Referring to Table 5, the No 2 deformation body is in the basically stable state. This agreed well with the preliminary analysis. Under continuous rainfall, the stability factor of strip 5 decreased to 0.92 , meaning that the No 2 deformation body is unstable under such conditions, which is in good agreement with the real situation.

Based on this analysis, the following conclusions can be drawn. The stability of the landslide and deformation bodies varied as the load conditions changed. From condition 1 (i.e. under the effect of the own weight of the slope) to condition 3 (i.e. under the effect of the own weight of the slope, rainfall, and seismic activity), the stability of the landslide varied from basically stable to less stable and finally to unstable; the stability of the No 1 deformation body varied from less stable to unstable; and the stability of the No 2 deformation body varied from basically stable to unstable. Due to the discrepancy of the slope in the study area, the deformation and stability variations have some differences; under some circumstances, partial failure may occur in the stable state. 


\section{Conclusions}

By means of field investigation ands model calculations, the following conclusions can be drawn. The stability of the unfavourable bodies was mainly affected by the 12 May 2008 Wenchuan Earthquake and subsequent rainfall infiltration. Continuous heavy rainfall plays a crucial role in slope stability analysis. In addition, human activity and weathering have also influenced the stability of unfavourable geological bodies in the study area.

Under natural conditions, the stability factor of the landslide ranges from about $1.02-$ 1.03, which means that this landslide is in the basically stable or less stable condition. Under the effect of continuous heavy rainfall, the stability factor of the landslide will be significantly reduced, and the corresponding value ranges from 0.9-0.96, which means that the landslide is in the unstable condition. For No 1 and No 2 deformation bodies, the stability varied from less stable to unstable, and basically stable to unstable, respectively.

At present, some of the unfavourable bodies are in the less stable state, under the effect of continuous heavy rainfall, seismic activity, or other influential factors; some geological bodies will probably change to the unstable state. Considering the property of the landslide itself, a cut slope is recommended as a preventative and mitigation measure. For the No 1 deformation body, anti-slide piles are recommended as prevention and mitigation measures. Due to the small volume and simplicity of the No 2 deformation body, it is recommended to clear it directly.

Acknowledgements. This work is financially supported by the National Natural Science Foundation of China (41302284 \&41661144028), the national Key R\&D Program of China (No. 2018YFC1505205), and the doctoral fund of Henan Polytechnic University (Grant No B2015-58).

\section{REFERENCES}

[1] Chen, B., Wei, L., Wu, C. (1989): Analysis on the method of pattern recognition on the development, distribution and the restrictive elements of debris flows in southwestern China. - Bulletin of Soil and Water Conservation 9(2): 54-56.

[2] Chen, N., Yang, C., Zhou, W., Hu, G., Li, H., Hand, D. (2009): The critical rainfall characteristics for torrents and debris flows in the Wenchuan earthquake stricken area. Journal of Mountain Science 6(4): 362-372.

[3] Chuan, T., Jing, Z., Xin, Q., Jun, D. (2011): Landslides induced by the Wenchuan earthquake and the subsequent strong rainfall event. A case study in the Beichuan area of China. - Engineering Geology 122: 22-33.

[4] Cui, P., Chen, X.-Q., Zhu, Y.-Y., Su, F.-H., Wei, F.-Q., Han, Y.-S., Liu, H.-J., Zhuang, J.-Q. (2011): The Wenchuan earthquake (May 12, 2008), Sichuan province, China, and resulting geohazards. - Natural Hazards 56(1): 19-36.

[5] GB 50330-2013 (2013): Technical Code for Building Slope Engineering. - National Standard of People's Republic of China.

[6] Hu, W., Dong, X. J., Xu, Q., Wang, G. H., van Asch, T. W. J., Hicher, P. Y. (2016): Initiation processes for run-off generated debris flows in the Wenchuan earthquake area of China. - Geomorphology 253: 468-477.

[7] Jiayuan, T. A. O. (1995): The distribution of disastrous debris flow in China. - Journal of Higher Correspondence Education (Natural Science) 4: 6-7.

[8] Kang, H.-S., Kim, Y.-T. (2016): The physical vulnerability of different types of building structure to debris flow events. - Natural Hazards 80(3): 1475-1493. 
[9] Lee, C. F., Huang, W. K., Chang, Y. L., Chi, S. Y., Liao, W. C. (2017): Regional landslide susceptibility assessment using multi-stage remote sensing data along the coastal range highway in northeastern Taiwan. - Geomorphology 300: 113-127.

[10] Ni, H. Y., Zheng, W. M., Tie, Y. B., Su, P. C., Tang, Y. Q., Xu, R. G., Wang, D. W., Chen, X. Y. (2011): Formation and characteristics of post-earthquake debris flow: a case study from Wenjia gully in Mianzhu, Sichuan, SW China. - Natural Hazards 61(2): 317335.

[11] Ni, H., Zheng, W., Tie, Y., Su, P., Tang, Y., Xu, R., Wang, D., Chen, X. (2012): Formation and characteristics of post-earthquake debris flow: a case study from Wenjia gully in Mianzhu, Sichuan, SW China. - Natural Hazards 61(2): 317-335.

[12] Postance, B., Hillier, J., Dijkstra, T., Dixon, N. (2017): Comparing threshold definition techniques for rainfall-induced landslides: a national assessment using radar rainfall. Earth Surface Processes \& Landforms. DOI: 10.1002/esp.4202.

[13] Shima, J., Moriyama, H., Kokuryo, H., Ishikawa, N., Mizuyama, T. (2016): Prevention and mitigation of debris flow hazards by using steel open-type Sabo dams. - International Journal of Erosion Control Engineering 9(3): 135-144.

[14] Sun, G., Huang, Y., Li, C., Zheng, H. (2016): Formation mechanism, deformation characteristics and stability analysis of Wujiang landslide near Centianhe reservoir dam. Engineering Geology 211: 27-38.

[15] Tang, C., Zhu, J., Li, W., Liang, J. (2009): Rainfall-triggered debris flows following the Wenchuan earthquake. - Bulletin of Engineering Geology and the Environment 68(2): 187-194.

[16] Wang, J., Yang, S., Ou, G., Gong, Q., Yuan, S. (2017): Debris flow hazard assessment by combining numerical simulation and land utilization. - Bulletin of Engineering Geology and the Environment77(1): 13-27.

[17] Wang, Y., Zhao, B., Li, J. (2017): Mechanism of the catastrophic June 2017 landslide at Xinmo Village, Songping River, Sichuan Province, China. - Landslides 4: 1-13.

[18] Zhuang, J., Cui, P., Hu, K., Chen, X., Ge, Y. (2010): Characteristics of earthquaketriggered landslides and post-earthquake debris flows in Beichuan County. - Journal of Mountain Science 7(3): 246-254.

[19] Zhuang, J.-Q., Cui, P., Peng, J.-B., Hu, K.-H., Iqbal, J. (2013): Initiation process of debris flows on different slopes due to surface flow and trigger-specific strategies for mitigating post-earthquake in old Beichuan County, China. - Environmental Earth Sciences 68(5): 1391-1403. 